\title{
Erratum to: Trend, variability, and outcome of open vs. laparoscopic appendectomy based on a large administrative database
}

\author{
Mario Saia $\cdot$ Alessandra Buja $\cdot$ Tatjana Baldovin • \\ Giampietro Callegaro $\cdot$ Paolo Sandonà • \\ Domenico Mantoan • Vincenzo Baldo
}

Published online: 13 March 2014

(C) Springer Science+Business Media New York 2014

\section{Erratum to: Surg Endosc (2012) 26:2353-2359 \\ DOI 10.1007/s00464-012-2188-5}

- On page 2353 in the abstract the sentence "The overall regional standardized appendectomy rate was 82.9/ 10,000." should be changed to "The overall regional standardized appendectomy rate was 91.12/100,000."

- On page 2354 in the results the sentence "The overall crude rate of hospitalization for appendectomy was 90.9/10,000." should be changed to "The overall crude rate of hospitalization for appendectomy was 90.9/ 100,000."
- On page 2355 in the results the sentence "Table 3 shows a significant linear declining trend in the rate of appendectomy procedures from 2000 to 2008 ( $\chi^{2}$ test for trend: 261.920; $P=0.000$ ), with a rate of $80.6 /$ 10,000 in the last year." should be changed to "Table 3 shows a significant linear declining trend in the rate of appendectomy procedures from 2000 to 2008 ( $\chi^{2}$ test for trend: 261.920; $P=0.000$ ), with a rate of $80.6 /$ 100,000 in the last year."

The online version of the original article can be found under doi:10. 1007/s00464-012-2188-5.

M. Saia · D. Mantoan

EuroHealth Net, Veneto Region Health Directorate, Palazzo

Molin, San Polo, 2513 - 30125 Venezia (VE), Italy

A. Buja $(\bowtie) \cdot$ T. Baldovin $\cdot$ P. Sandonà $\cdot$ V. Baldo Department of Environmental Medicine and Public Health, University of Padova, Via Loredan, 18, 35128 Padova, Italy e-mail: alessandra.buja@unipd.it

G. Callegaro

EuroHealth Net, Local Health Unit $\mathrm{N}^{\circ} 8$, Via Forestuzzo 41,

31011 Asolo, Veneto Region, Italy 